\title{
Plantas medicinais como alternativa para o estudo de taxonomia e funções orgânicas no Ensino Médio
}

Medicinal plants as an alternative for the study about taxonomy and organic functions in high school

\author{
Elisandra Brizolla de Oliveira \\ Biagio Sartori Sampaio \\ Amabele Figueiredo Gomes Borges \\ Franklin Noel dos Santos
}

\begin{abstract}
Resumo: O uso de plantas medicinais faz parte do cotidiano dos alunos da Escola Estadual do Município de Pinheiros-ES e suas famílias, que as utilizam levando em conta o conhecimento popular sobre seu poder de cura. Nesse contexto, a construção de um horto-medicinal na escola possibilita a visualização e contextualização prática de alguns conteúdos da área de Ciências da Natureza, em especial a Biologia e a Química. Este trabalho objetivou identificar e coletar as plantas medicinais de uso popular entre as famílias dos estudantes em uma Escola Estadual no Município de Pinheiros/ES, para servir de aporte teórico-metodológico no ensino de taxonomia e funções orgânicas, presentes nos princípios ativos contidos nas plantas, além de conhecer as propriedades terapêuticas para conscientizar os alunos sobre propriedades medicinais e o perigo do seu uso abusivo ao organismo, além de reproduzir as espécies mais utilizadas pelas famílias da comunidade. Buscou-se, ainda, utilizar a proposta para promover a integração das áreas e elevar a participação e interesse nas disciplinas de Biologia e Química. Para efetivação do projeto, foi realizada a pesquisa de campo por meio de entrevistas e coletas das plantas medicinais pelos estudantes do $3^{\circ}$ ano do Ensino Médio. As plantas coletadas foram identificadas e classificadas, reproduzidas em um horto-medicinal construído com materiais reaproveitados encontrados na escola, permitindo trabalhar de forma interdisciplinar na construção e embelezamento estético, por meio de canteiros suspensos, para otimização de espaços. A construção do horto medicinal contribuiu para os estudos de taxonomia e das funções orgânicas, além de potencializar aprendizagem significativa e contextualizada por meio do conhecimento e uso de espécies medicinais.
\end{abstract}

Palavras-chave: plantas medicinais; interdisciplinaridade; taxonomia; funções orgânicas.

Abstract: The use of medicinal plants is part of the students' daily and their families, who use popular knowledge about its healing power. In this context, the construction of a Medicinal Garden enables answers and practical contextualization of some contents in the Area of Natural Sciences, especially Biology and Chemistry. This work aims to identify and collect medicinal plants of popular use among students' families of a State School in the county of Pinheiros/ES, to serve as theoretical contributionmethodological method in the teaching of taxonomy and organic functions, present in the active principles contained in plants, in addition to being known as therapeutic properties to make students aware about medicinal properties and the danger of abuse of the organism, besides reproducing the most used species by families in the community. The objective was also to use the proposal to promote the integration of areas and increase the results in the disciplines. To make this work possible, field research was carried out through interviews and collections of medicinal plants by the 
students of the 3rd year of High School. The collected plants were identified and classified, reproduced in medicinal gardens, built with reused materials found in the school, allowing them to work in an interdisciplinary way in the construction and aesthetic beautification through suspended beds to optimize spaces. The construction of the medicinal garden has contributed to studies of taxonomy and organic functions, in addition to improving meaningful and contextualized learning through the knowledge and use of medicinal species.

Keywords: Medicinal plants. Interdisciplinarity. Taxonomy; Organic functions.

\section{Contextualização e justificativa do Projeto}

Segundo Ausubel, (1978) para a aquisição de uma aprendizagem significativa deve haver alguma associação entre o novo conhecimento e aquele já existente na estrutura cognitiva do aluno. Mas afinal o que é "aprendizagem significativa"? Ausubel (1978), define, aprendizagem significativa como aquela em que ideias expressas simbolicamente interagem de maneira substantiva e não-arbitrária com aquilo que o aprendiz já sabe. Para ele, aprender significativamente é ampliar e reconfigurar ideias já existente na estrutura mental e com isso ser capaz de relacionar e acessar novos conteúdos, ou seja, aprendizagem com significado para o aluno.

Neste contexto, planejamos o projeto “PLANTAS MEDICINAIS COMO ALTERNATIVA PARA O ESTUdO DE TAXONOMIA E FUNÇÕES ORGÂNICAS NO ENSINO MÉDIO", com o objetivo de utilizar do conhecimento prévio e cultural dos estudantes e suas respectivas famílias de forma que houvesse uma participação ativa do aluno, uma vez que se trata de um processo por meio do qual uma nova informação relaciona-se, com uma préexistente. O presente projeto foi pensando a partir da relação prática e teoria, construindo coletivamente um ortomedicinal em um espaço do pátio da Escola, no qual foram plantadas e identificadas as principais plantas, com propriedades terapêuticas, utilizada pelos estudantes e suas famílias

Ao trabalhar o ensino de Taxonomia, em Biologia, com os estudantes do $3^{a}$ série do Ensino Médio de uma escola estadual, localizada no extremo norte do Espírito Santo, senti a necessidade de contextualizar o assunto, com situações comuns do dia a dia e que facilitasse a compreensão de termos científicos. Ao mesmo tempo, entendo que, trabalhar de forma interdisciplinar, 
e contextualizada, ressignifica conhecimentos e torna-se potencializador de aprendizagens (BRIZOLLA, 2016).

Partindo do pressuposto de que os conteúdos de classificação taxonômica e funções orgânicas são trabalhados, muitas vezes, de modo memorístico e fragmentados, sendo provável que não façam sentido para os estudantes, corroborando com as inferências de Brizolla(2016), percebi a oportunidade de trabalhar conceitos científicos de uma forma prática, possibilitando associação entre o novo conhecimento e aquele já existente, além de promover a integração das áreas de conhecimento, conforme a Organização Curricular Estadual. A proposta do projeto foi elaborado pelas docentes responsáveis pelas disciplinas de Biologia e Química e apresentada para os professores da área de Ciências da Natureza e equipe pedagógica da escola, buscando conciliar o projeto com o currículo básico para a $3^{a}$ série do Ensino Médio.

Na perspectiva de potencializar os conhecimentos partindo da realidade dos estudantes, buscamos por meio da pesquisa-ação (THIOLLENT, 1988), um viés de investigação social, mesmo que de forma empírica, utilizando de entrevistas, como resgate cultural do uso das ervas medicinais, assim como, utilizar dos resultados desta pesquisa, tais como: quais as plantas mais utilizadas pela família, seu uso e como identificam ou nomeiam essas plantas? para a construção de um horto-medicinal, espaço onde se pudesse expressar a criatividade dos estudantes, o reaproveitamento de materiais, além de contextualizar o ensino dos conteúdos trazidos pela Taxonomia, por meio da identificação das plantas coletadas para a reprodução no horto medicinal, além de possibilitar o estudo das funções orgânicas e propriedades medicinais e tóxicas das plantas.

A escola é um espaço privilegiado para experimentar situações, favorecendo a elaboração e aplicação de projetos que promovam o desenvolvimento integral do estudante, ou seja, auxilia na construção de conhecimento e, ao mesmo tempo, atua como entidade que resgata culturas e dissemina a consciência ambiental, passando a ser o ambiente ideal para aplicação desta prática. Nossa inferência se pauta nas proposições de Luck 
(1995, p. 64) ao destacar que "[...] o processo de integração e engajamento de educadores, num trabalho conjunto, de interação das disciplinas do currículo escolar entre si e com a realidade, de modo a superar a fragmentação do ensino, objetivando a formação integral dos alunos [...]."

Considerando a relevância dos conteúdos da Taxonomia, para a ecologia, agricultura, agronomia, botânica, zoologia, entendemos que esses conceitos se configuram como norteadores e necessários, na perspectiva de uma aprendizagem significativa e contextualizada. Vislumbramos que a implementação deste projeto potencializa a tentativa de propor aos estudantes a contextualização científica, valorizando não somente a contextualização, mas aproximando os jovens da pesquisa científica e sua importância, afinal, aprender Ciência não é só aprender conceitos e modelos, é também praticar de alguma forma o trabalho científico.

Amorim (2002) destaca a Taxonomia como "estudo teórico da classificação, incluindo as respectivas bases, princípios, normas e regras".. Neste sentido, a Taxonomia traz conteúdos essenciais para fundamentação teórica, entre o conceito de espécie, as categorias taxonômicas, regras de nomenclatura e árvores filogenéticas com as plantas medicinais cultivadas no horto medicinal.

A Química, assim como as demais disciplinas que compõem a área de Ciências da Natureza, não é uma ciência pronta e acabada, mas sim em constante elaboração/construção do conhecimento (CHASSOT, 1995).

De acordo Oliveira (2010), conforme citado Silva $(2011$, p.6) a busca de novas perspectivas para o ensino de química, requer mudanças na proposta metodológica, ou seja,

[...] entende-se que a melhoria da qualidade do ensino de Química passa pela definição de uma metodologia de ensino que privilegie a contextualização como uma das formas de aquisição de dados da realidade, oportunizando ao aprendiz uma reflexão crítica do mundo e um envolvimento de forma ativa, criadora e construtiva com os conteúdos abordados em sala de aula [...] (OLIVEIRA 2010)". 
Segundo os autores supracitados, acredita-se numa abordagem de ensino de Química voltada à construção e reconstrução de significados dos conceitos científicos nas atividades de sala de aula, alocando-a não apenas à Química como ciência, mas também no contexto escolar.

É comum, no cotidiano escolar, o aluno comentar que, quando tem alguma indisposição, como dores de cabeça e dor de estômago, a família geralmente recorre a chás para aliviar os sintomas. $O$ uso de plantas medicinais é baseado no conhecimento popular, que foi passado de geração a geração, entretanto, sem o conhecimento científico a respeito da real eficácia da planta. Neste contexto utilizar o tema plantas medicinais para trabalhar conteúdos de classificação taxonômica e funções orgânicas é de grande importância, uma vez que está diretamente relacionado ao cotidiano do aluno.

A escolha por plantas medicinas, que segundo Martins et al., (2003), são dotadas "substâncias com ação terapêutica", para o desenvolvimento da proposta se deu pela relação do uso e conhecimento popular pelas famílias dos estudantes, o que facilitaria a contextualização e a identificação científica, partindo da pesquisa dos nomes populares das espécies utilizadas com fins terapêuticos.

Concordando com Fagundes, Oliveira e Souza (2017), afirmamos que por meio da Etnobotânica, busca-se o conhecimento e o resgate do saber botânico tradicional, possibilitando integrar o conhecimento empírico ao acadêmico, desempenhando papel importante no resgate e valorização da cultura local. Os conhecimentos tradicionais são transmitidos e mantidos principalmente pela oralidade, neste contexto, os estudos etnobotânicos, são importantes ferramentas para o seu resgate e registro, evitando, assim, que se percam ao longo do tempo, além de potencializar o trabalho com a identificação sistemática das plantas coletadas.

A escola, enquanto espaço de formação de consciência crítica, deve estar estruturada no sentido de prover ao seu corpo discente formação integrada e contextualizada, pois, só assim, estará cumprindo a sua função social, conforme Freire (1996). Sendo assim, a prática da interdisciplinaridade tem como propósito colaborar na reorganização do conhecimento partindo de 
uma dinâmica investigativa que envolve a participação de diferentes disciplinas sobre um eixo integrador, que propicie a oportunidade de trabalhar em conjunto. Fazenda (2008) define "interdisciplinaridade como atitude de ousadia e busca frente ao conhecimento, cabendo aos educadores pensar aspectos que envolvem a cultura científica e religuem conceitos fragmentados pelo ensino disciplinar". Vale destacar os argumentos de Oliveira e Santos (2017, p.79), ao defenderem a interdisciplinaridade, não apenas como uma proposta teórica ou necessidade teórica, mas como uma ação prática que se aperfeiçoa à medida que são realizadas experiências de trabalho coletivo.

A construção de um horto medicinal, além de se apresentar como uma proposta de trabalho interdisciplinar, possibilita aos professores desenvolverem diversas atividades pedagógicas, não apenas na área das Ciências da Natureza, mas na Linguagem, Humanas e Matemática, incluindo a educação ambiental. Segundo MORGADO (2006), hortas inseridas em um ambiente escolar contextualizam e auxiliam o processo de ensino-aprendizagem, além de estimular o trabalho coletivo entre alunos e professores.

\section{Material e método}

O processo de ensino-aprendizagem, Conforme Moran (2008), requer dinamismo por parte do professor, ou seja, exige hoje muito mais flexibilidade no espaço-tempo, da equipe e da pessoa, e menos conteúdos fixos, solicitando processos mais abertos de pesquisa e comunicação. Dessa forma, o projeto de pesquisa-ação teve, como finalidade incentivar o aluno a buscar informações sobre plantas medicinais de uso comum em suas famílias, de maneira que ele próprio fosse sujeito de sua aprendizagem, em concordância com as inferências de Mattos e Castanha (2009), ao destacarem que pesquisa propicia o espírito investigativo, desenvolve a reflexão sobre o assunto, aumenta a capacidade de argumentação e torna a aula mais atrativa para o aluno.

O projeto "PLANTAS MEDICINAIS COMO ALTERNATIVA PARA O ESTUDO DE TAXONOMIA E FUNÇÕES ORGÂNICAS NO ENSINO MÉDIO", inicialmente foi apresentado aos estudantes do $3^{\text {a }}$ série do Ensino Médio, do turno matutino de uma escola estadual no Município de Pinheiros, Espírito 
Santo, em abril de 2019, como parte integrante dos estudos de Taxonomia, conteúdo programático previsto no currículo escolar, na disciplina de Biologia. Percebemos a necessidade de integrar não somente a área de Ciências da Natureza, como a área de Ciências Humanas e Linguagem, na perspectiva de potencializar aprendizagens.

$\mathrm{Na}$ perspectiva do desenvolvimento de uma pedagogia dialógica considerando os saberes populares e os aparatos científicos de fácil acesso é que pensamos o referido projeto e, para isso, foram convidados os professores de Ciências da Natureza, Matemática e Arte. A proposta ganhou representatividade e foi aceita por parte do grupo.

A sensibilização os alunos foi feita por meio de uma palestra (Foto 1 e 2) intitulada "O que são plantas medicinais? Conhecendo suas formas de Utilização e suas propriedades Terapêuticas", com a participação de uma enfermeira especialista em terapias florais, que apresentou as ervas medicinais, seus princípios ativos, possíveis efeitos colaterais pelo uso inadequado ou falta de conhecimento, assim como as formas de preparo, chás e tinturas.

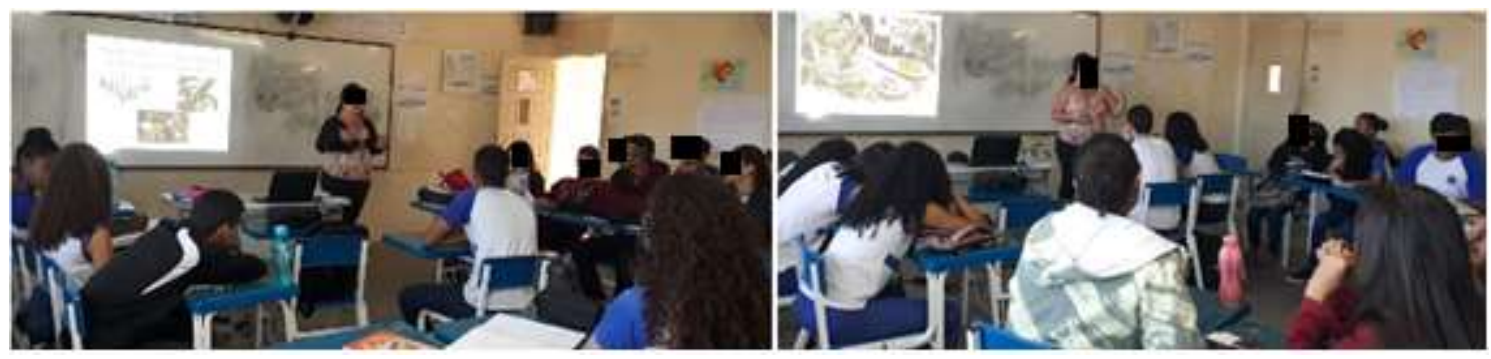

Foto 1 e 2: Palestra $3^{\circ}$ M01 e $3^{\circ} \mathrm{M} 02$ - "O que são plantas medicinais? Conhecendo suas formas de Utilização e suas propriedades Terapêuticas.

A partir da palestra, os estudantes foram motivados a pesquisarem junto à comunidade local as plantas medicinais que mais eram utilizadas $\mathrm{e}$ finalidades (as funções terapêuticas), assim como fazer uma pesquisa bibliográfica sobre o uso das plantas medicinais. Para isso, utilizou-se um questionário semi-estruturado, contendo um roteiro para a entrevista, com o objetivo de fazer o levantamento das plantas de uso medicinal popular pela comunidade escolar. Dentre as diversas técnicas de pesquisa social, o questionário é a forma mais usada segundo Cervo, Bervian e Silva (2007), pois 
possibilita verificar com exatidão o que se deseja pesquisar, ou seja, formulamse perguntas com objetivo de contribuir para o trabalho de pesquisa.

Para este estudo foram registrados 74 questionários, respondidos pelas famílias dos estudantes, referente ao quantitativo de estudantes matriculados $3^{a}$ série do Ensino Médio, sobre as plantas medicinais mais usadas pelas famílias dos alunos, com 05 questões, abertas e fechadas, conforme o quadro abaixo.

\section{PLANTAS MEDICINAIS COMO ALTERNATIVA PARA O ESTUDO DE SISTEMÁTICA: CLASSIFICAÇÃO FILOGENÉTICA E FUNÇÕES ORGÂNICAS NO ENSINO MÉDIO}

Em sua casa, quando alguém apresenta alguma indisposição, é utilizado algum tipo de planta medicinal?

( ) $\operatorname{sim}($ ) não - Caso tenha respondido sim à pergunta anterior, qual ou quais plantas são usadas? -

Como é o preparo? $($ ) chás () xaropes () outros

Você confia na eficácia das plantas medicinais? ( ) sim ( ) não ( ) as vezes

De onde veio o conhecimento sobre o uso de plantas medicinais em sua família? ( ) pais ( ) avós ( ) vizinhos ( ) livros ( ) outros

Você sabia que algumas plantas medicinais podem apresentar efeitos colaterais indesejados e até mesmo serem tóxicas? Quanto ao manuseio, preparo de chás, e armazenamento? ( ) sim ( ) não

Quadro 1: Questionário semi-estruturado para entrevista com as famílias sobre o uso e conhecimento das plantas medicinais.

Dando continuidade às atividades propostas para o projeto, os alunos foram divididos em grupos e cada grupo pesquisou sobre uma planta, que apareceram nos questionários, à distribuição tanto dos grupos quanto das plantas a serem pesquisadas, se deu, por sorteio. Foram indicados os pontos a serem pesquisados: Identificação - nome popular, nome científico; família; parte usada; indicação; composição química e princípios ativos presentes com 
sua respectiva fórmula estrutural plana. Como na escola, em questão, toda a atividade executada, deve ser avaliada, a modalidade seminário foi escolhida, por ser uma atividade dinâmica em que há envolvimento ativo de todos os alunos, para contar como atividade de participação, socialização dos resultados da pesquisa bibliográfica, além de direcionar a escolha das plantas a serem plantadas no horto medicinal. A escolha se deu ainda pelo tempo de execução do projeto, conforme previsto no Plano de Ensino e Plano de Ação da Escola, considerando o fechamento do trimestre. A síntese desta etapa estão descritas nos Quadros 2 e 3 .

Esta etapa do projeto serviu de base para a seleção das plantas a serem plantadas no horto, além de requisito para a oficina teórico-prática "Produção de substrato" (Foto 3), com a participação de um professor mestre Em Agricultura Tropical e estudante de Agronomia. A oficina contou com uma roda de conversa e preparação para a execução da prática, contendo os seguintes pontos: fertilidade do solo; tipos de compostos; formulação de substrato; construção de hortas orgânicas. Durante a aplicação da oficina, produziu-se o substrato, a ser utilizado para o plantio das mudas, a partir da matéria orgânica residual obtida na usina de compostagem do município, esterco bovino, palha de café e terra, produtos adquiridos junto à comunidade.

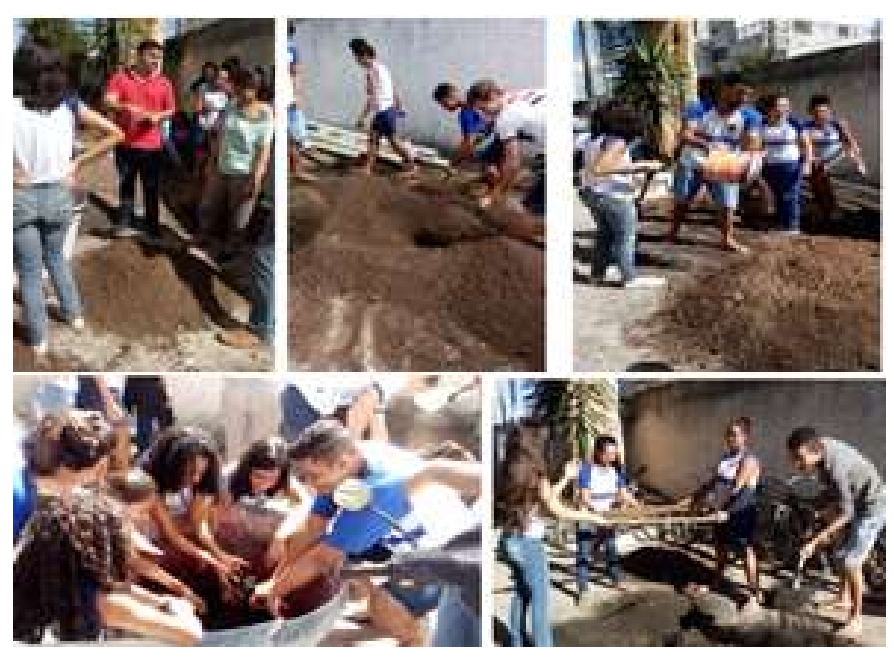

Foto 3 Oficina "Produção de substrato para plantio das plantas medicinais".

Além da pesquisa de campo, os estudantes foram orientados a realizar uma pesquisa de fundamentação teórica, sobre a construção de hortos 
medicinais, tipos de composto para cultivo das plantas coletadas, assim como utilizar do nome popular para realizar a classificação científica e identificação dos princípios ativos em cada uma das amostras. Os resultado foram sintetizados nos Quadros 2 e 3.

\section{Mãos à obra: Preparo, Plantio e Identificação das Plantas Medicinais}

Partindo da pesquisa dos estudantes, considerando que a escola não disponibiliza de espaço ou área aberta para que fosse implantado o projeto, optou-se pela proposta de hortas suspensas, pela otimização do espaço (Foto 3) em uma área $75 \mathrm{~m}^{2}$. A escolha desse espaço se deu pela proximidade de água e energia elétrica, para que fosse instalado um sistema de irrigação alternativo e automatizada, como uma contribuição da disciplina de Física.
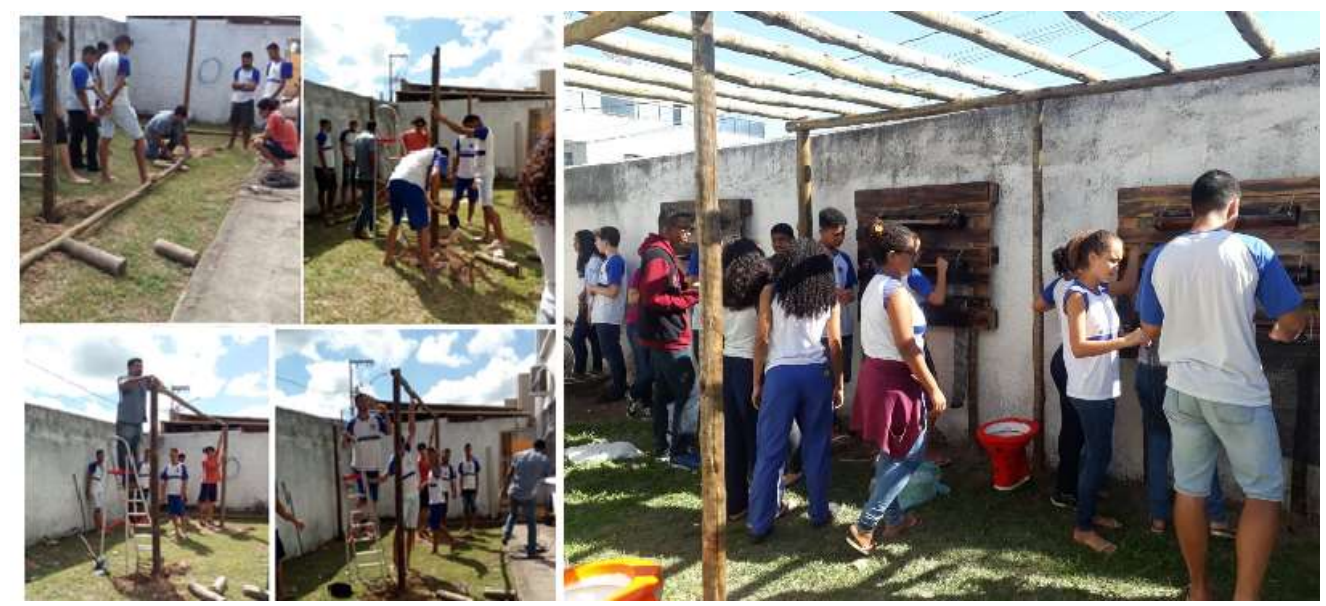

Foto 4: Escolha da área, construção do horto, plantio das espécies coletadas.

Procuramos materiais alternativos e recicláveis para utilizarmos como vasos, dando-lhes um destino de reutilização, além de possibilitar a criatividade dos estudantes nas aulas de Arte (Foto 5). A professora de Arte utilizou o documentário "Lixo Extraordinário", de Viky Muniz, para sensibilizar a turma para $\circ$ trabalho de reciclagem. De posse dos exemplares das plantas medicinais coletados e trazidos pelos alunos, foram plantadas em canos pvc, vasos sanitários e lavatórios (reaproveitados da reforma da quadra esportiva da escola) que foram previamente preparados. 


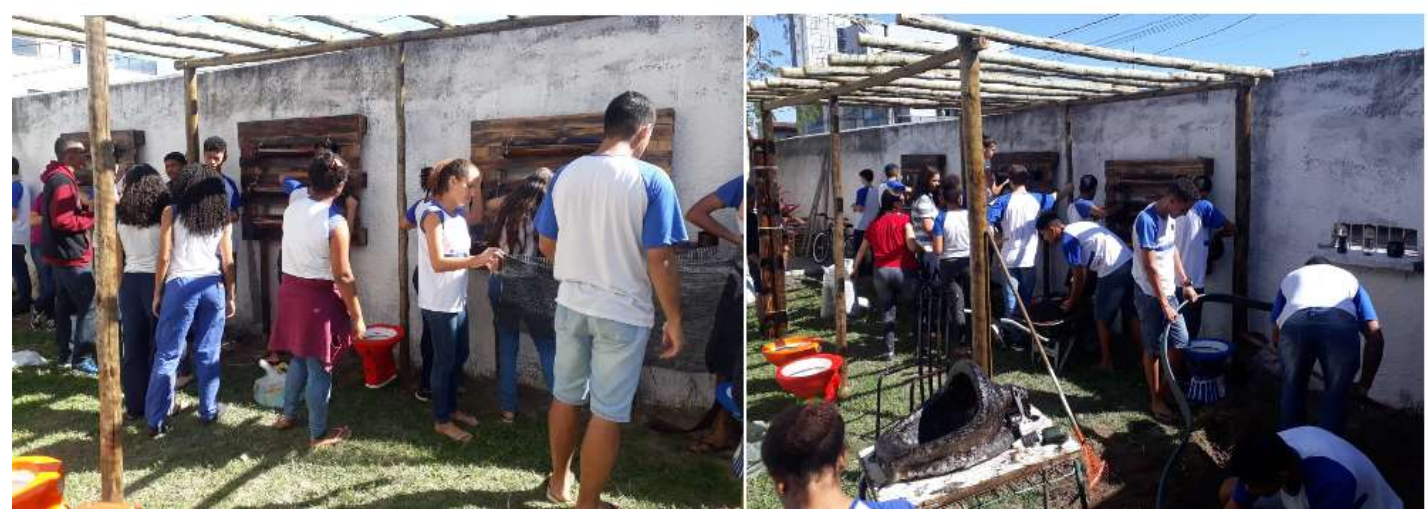

Foto 5: Escolha e preparo de materiais para o plantio das mudas.

Tendo como base as plantas mais utilizadas pelas famílias dos estudantes, (Gráfico 1), buscamos junto à comunidade mudas, para que pudéssemos identificar e reproduzir em nosso horto medicinal.

A finalização do trabalho possibilitou o plantio de alguns dos exemplares das plantas medicinais, conseguidos com as famílias e comunidade, e a respectiva identificação taxonômica, realizada pelos estudantes através da pesquisa e registradas nas placas de madeira e identificadas com auxilio de pirógrafo.

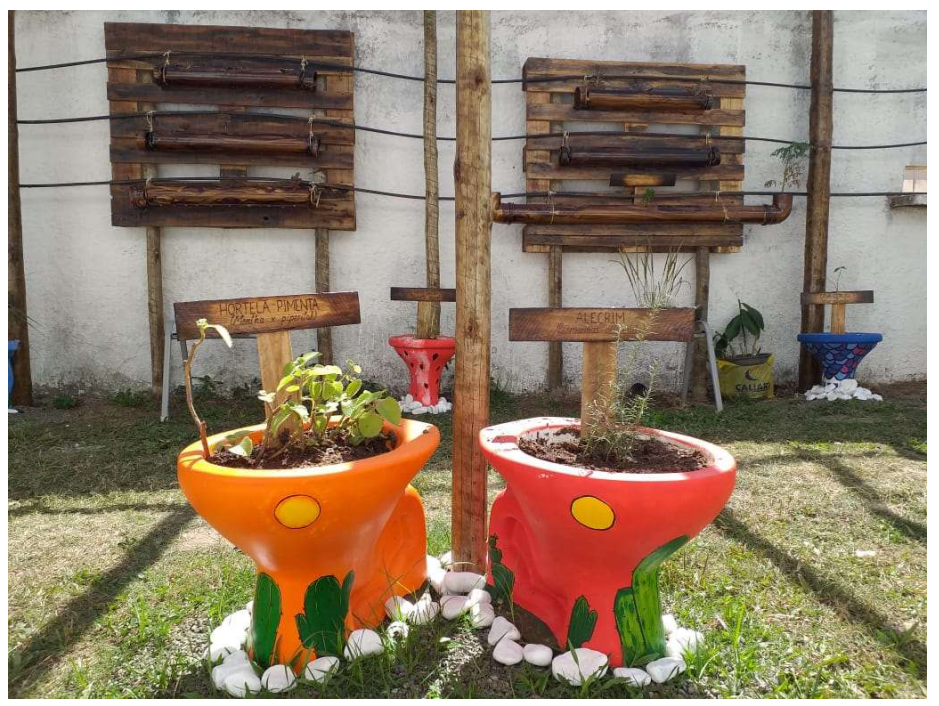

Foto 6: Plantio e identificação das plantas medicinais

\section{Resultados e Discussão}

De posse dos questionários já respondidos, os alunos apresentaram os resultados obtidos, utilizando gráficos e planilhas como recurso de interpretação estatístico e de visualização, o que evidenciou que todos os 
respondentes do questionário fazem uso de plantas medicinais. Os resultados estão demonstrados no Gráfico 1.

Plantas Medicinais mais utilizadas pelas famílias dos alunos

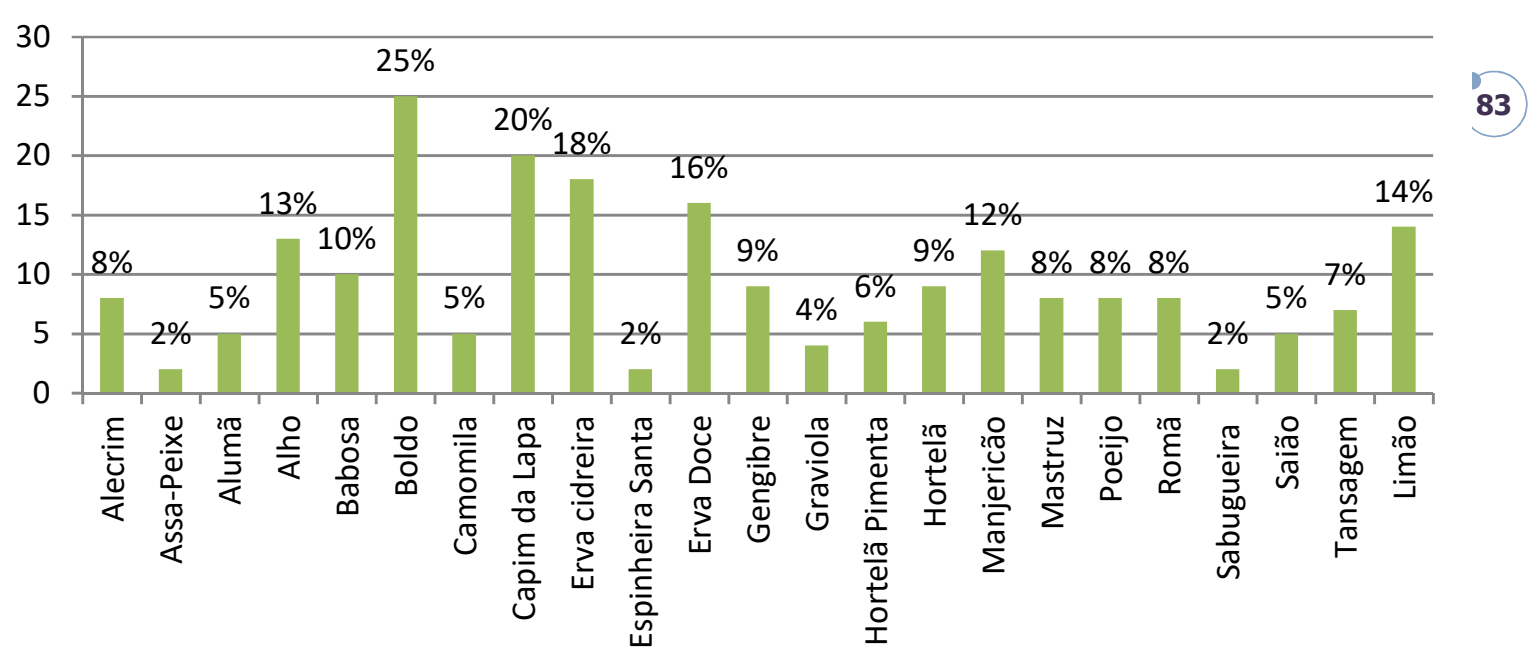

Gráfico 1: Plantas Medicinais mais utilizadas pelas famílias dos alunos

Os resultados apresentados evidenciam que, entre as famílias, as plantas mais utilizadas são Boldo (Peumus boldus), capim da lapa (Cymbopogon citratus), erva-cidreira (Melissa officinalis) e erva-doce (Pimpinella anisum), sendo o chá a forma de utilização mais utilizada, entretanto, não foi especificada a forma como o chá é feito, ou seja, não houve registro de respostas nos questionários aplicados. Também evidenciou as plantas menos utilizadas, uma hipótese, é pela falta de conhecimento, ou pela dificuldade de serem encontradas, pois, não obtivemos exemplares para serem cultivadas no horto medicinal.

Quando perguntados de onde veio o conhecimento do uso das plantas medicinais na família, a grande maioria relata que os avós foram os responsáveis pelo conhecimento do uso medicinal como a forma de preparo dos chás, conforme apresentado no Gráfico 2. 


\section{Conhecimento sobre o uso das plantas medicinais}

na família

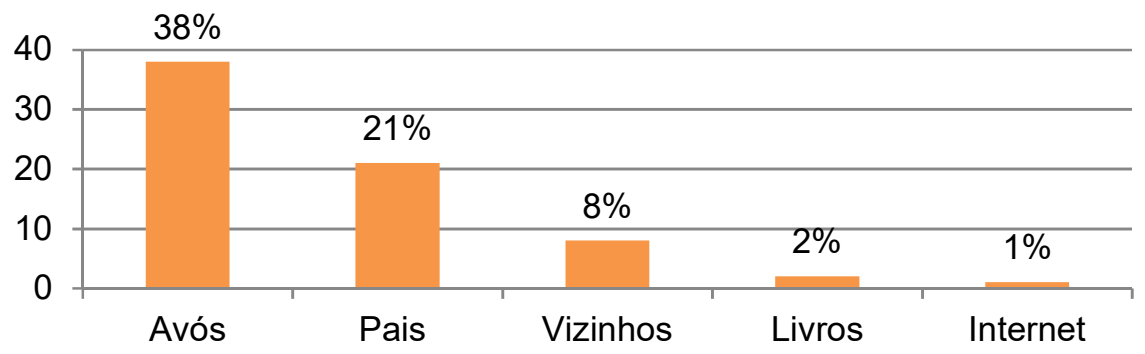

Gráfico 2: Conhecimento sobre o uso das plantas medicinais na família

Um resultado que chama a atenção foi o baixo número de entrevistados que utilizam a internet para procurar informações sobre o uso de plantas medicinais, inclusive pelo acesso à informação que a internet proporciona, foi quanto o número de famílias que desconhecem os efeitos colaterais e toxicidade das plantas, quando manuseadas, armazenadas ou preparadas de forma inadequada, sendo que $39 \%$ entrevistados declaram não ter conhecimento sobre uma possível toxicidade das plantas medicinais. Todavia, a maioria conhece os possíveis efeitos, assim como a forma correta de preparo.

Entre as pessoas entrevistadas, a maioria relata acreditar no uso das ervas medicinais para aliviar sintomas de doenças, do trato digestivo, resfriados, vermes, entre outros.

Após amplo debate mediado pelas professoras de Biologia e Química sobre os resultados obtidos a partir dos questionários, foi proposto o tema: "A química presente nas plantas medicinais", em que foram explorados os conceitos relativos aos princípios ativos e como a planta sintetiza os metabólitos secundários, além de pesquisa teórica sobre a toxicidade nas plantas. Esse resultado nos indicou a necessidade de trabalhar o tema em sala, uma vez que falas isoladas dos estudantes ressaltavam que "chás ou aquilo que vem da natureza não faz mal" As professoras, responsáveis pelo projeto, organizaram uma apresentação, utilizando slides como o tema: "Conheça os riscos e os benefícios do uso de plantas medicinais". Foram 
utilizado as plantas que foram evidenciadas na pesquisa, para que a temática fosse que sejam disseminados entre as famílias.

Os questionários evidenciaram as plantas mais utilizadas e serviram de base para a construção dos Quadros 1 e 2.

Quadro 1: Plantas medicinais e princípios ativos pesquisados.

\begin{tabular}{|c|c|c|c|c|}
\hline $\begin{array}{l}\text { Nome } \\
\text { popular }\end{array}$ & $\begin{array}{l}\text { Nome } \\
\text { Científico }\end{array}$ & $\begin{array}{l}\text { Princípio } \\
\text { Ativo }\end{array}$ & $\begin{array}{c}\text { Fórmula Estrutural e } \\
\text { Molecular }\end{array}$ & $\begin{array}{l}\text { Funções } \\
\text { Orgânicas }\end{array}$ \\
\hline Alecrim & $\begin{array}{l}\text { Rosmarinus } \\
\text { officinalis }\end{array}$ & $\begin{array}{l}\text { Óleos } \\
\text { essenciais; } \\
\text { Terpenóides; } \\
\text { Flavanóides }\end{array}$ & $\begin{array}{c}\mathbf{R 2} \\
\text { Fórmula: } \mathrm{C}_{1}\end{array}$ & $\begin{array}{c}\text { Aldeido } \\
\text { e } \\
\text { Éster }\end{array}$ \\
\hline $\begin{array}{l}\text { Assa- } \\
\text { Peixe }\end{array}$ & $\begin{array}{l}\text { Vernonia } \\
\text { polyanthes }\end{array}$ & Flavanoides & Fórmula: $\mathrm{C} 15 \mathrm{H} 10 \mathrm{O} 6$ & $\begin{array}{l}\text { Fenol e } \\
\text { Éster }\end{array}$ \\
\hline $\begin{array}{l}\text { Nome } \\
\text { popular }\end{array}$ & $\begin{array}{l}\text { Nome } \\
\text { Científico }\end{array}$ & $\begin{array}{l}\text { Princípio } \\
\text { Ativo }\end{array}$ & $\begin{array}{l}\text { Fórmula Estrutural e } \\
\text { Molecular }\end{array}$ & $\begin{array}{l}\text { Funções } \\
\text { Orgânicas }\end{array}$ \\
\hline $\begin{array}{l}\text { Alumã } \\
\text { ou Boldo } \\
\text { Baiano }\end{array}$ & $\begin{array}{l}\text { Vernonia } \\
\text { condensata }\end{array}$ & $\begin{array}{c}\text { Ácido } \\
\text { clorogênico }\end{array}$ & Fórmula: $\mathrm{C}_{16} \mathrm{H}_{18} \mathrm{O}_{9}$ & $\begin{array}{l}\text { Éster e } \\
\text { Fenol }\end{array}$ \\
\hline Alho & Allium sativum & Alicina & $\begin{array}{l}\mathrm{H}_{2} \mathrm{C}={ }_{\mathrm{O}}^{\mathrm{S}} \mathrm{NH}_{2} \\
\text { Fórmula: } \mathrm{C}_{6} \mathrm{H}_{11} \mathrm{NO}\end{array}$ & $\begin{array}{l}\text { Ácido } \\
\text { Sulfinotióico } \\
\text { e Éster }\end{array}$ \\
\hline Babosa & Aloe vera & Acemanana & Fórmula: $\mathrm{C}_{66} \mathrm{H}_{100} \mathrm{NO}_{49}$ & Nitrocomposto \\
\hline
\end{tabular}




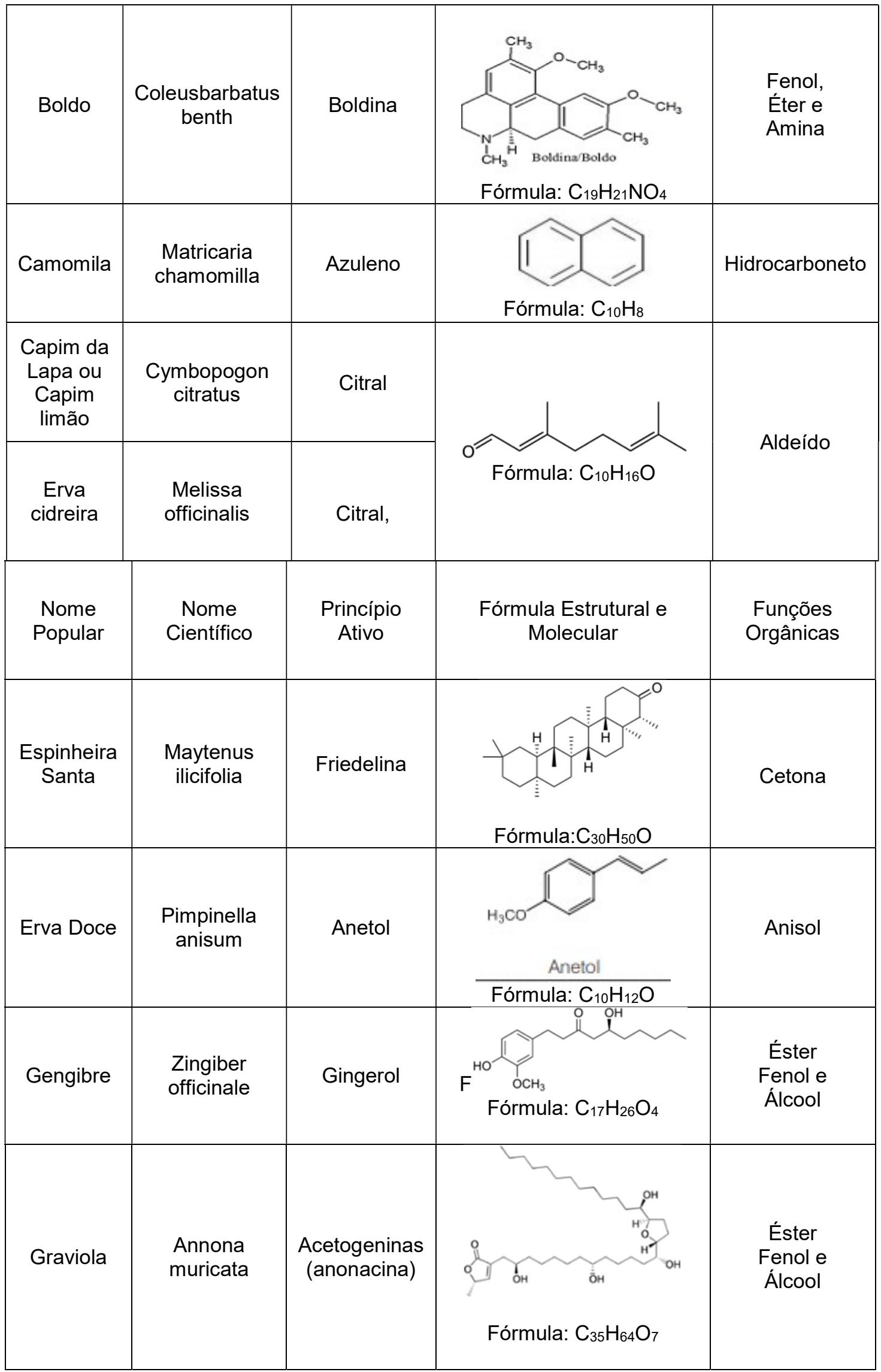




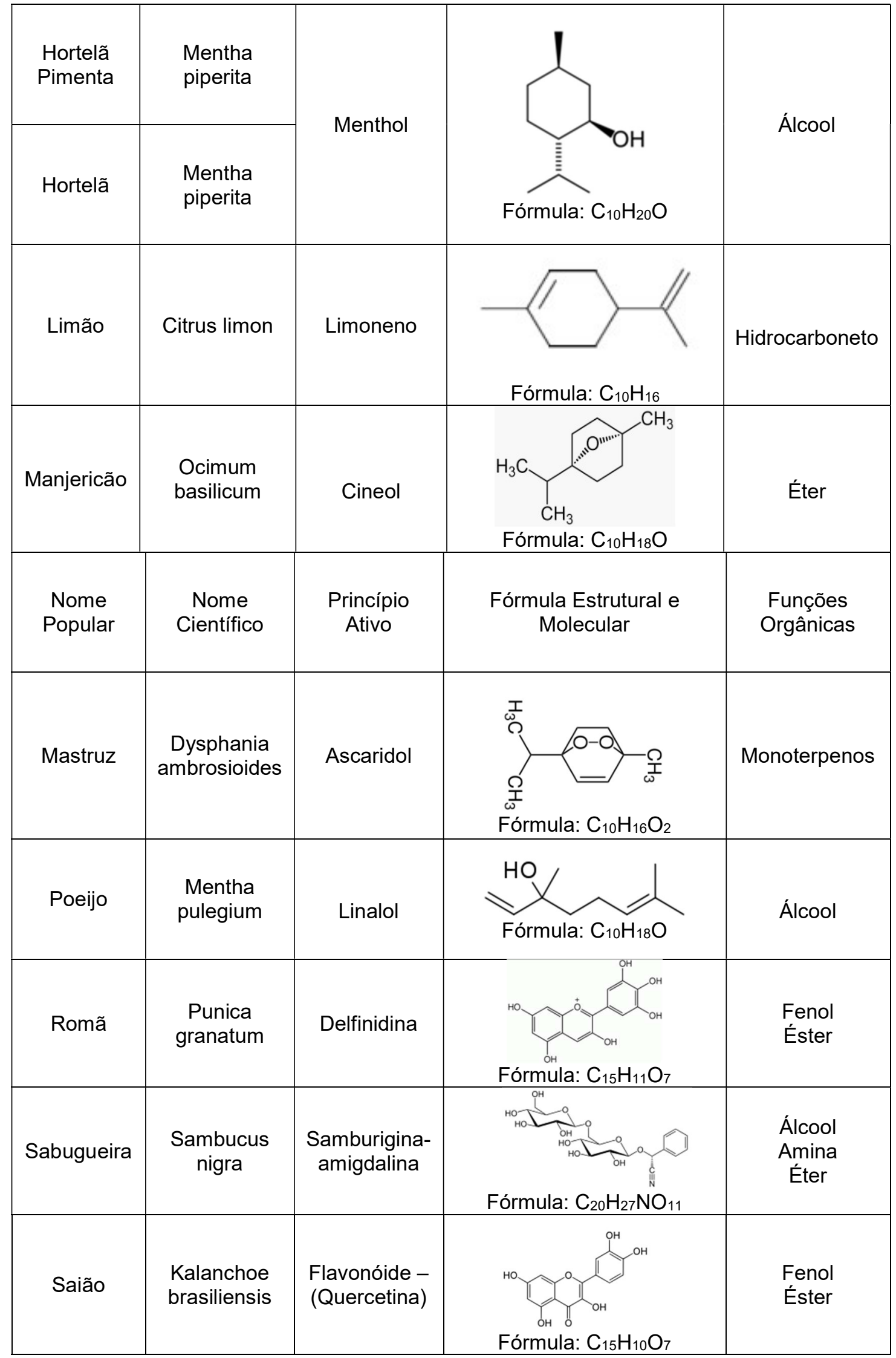




\begin{tabular}{|c|c|c|c|c|}
\hline $\begin{array}{c}\text { Tansagem } \\
\text { ou } \\
\text { Tanchagem }\end{array}$ & $\begin{array}{c}\text { Plantago } \\
\text { major }\end{array}$ & Aucubina & $\begin{array}{c}\text { Álcool } \\
\text { Éster } \\
\text { Fórmula: } \mathrm{C}_{15} \mathrm{H}_{22} \mathrm{O}_{9}\end{array}$ & SOH \\
\hline
\end{tabular}

O Quadro 2 descreve, de forma resumida, o estudo dirigido apresentado pelos estudantes, contendo as principais propriedades terapêuticas das ervas medicinais utilizadas entre as famílias, embasado na obra de Grandi (2017), e pesquisa na internet de livre busca.

Quadro 2: Propriedades terapêuticas das ervas medicinais.

\begin{tabular}{|c|c|c|}
\hline $\begin{array}{l}\text { Nome } \\
\text { Popular }\end{array}$ & $\begin{array}{c}\text { Nome } \\
\text { Científico }\end{array}$ & Propriedades Terapêuticas \\
\hline Alecrim & Rosmarinus officinalis & $\begin{array}{l}\text { Estimulante digestivo, antiespasmódica, } \\
\text { estomacal, vasodilatadora, antisséptica, } \\
\text { antidispéptica, anti-inflamatória. }\end{array}$ \\
\hline Assa-Peixe & Vernonia polyanthes & Tônica, diurética, expectorante \\
\hline $\begin{array}{l}\text { Nome } \\
\text { Popular }\end{array}$ & $\begin{array}{c}\text { Nome } \\
\text { Científico }\end{array}$ & Propriedades Terapêuticas \\
\hline $\begin{array}{l}\text { Alumã ou } \\
\text { Boldo Baiano }\end{array}$ & Vernonia condensata & $\begin{array}{l}\text { Antidispéptico, analgésico, sedativo, } \\
\text { aperiente, tônico, hepatoprotetor. }\end{array}$ \\
\hline Alho & Allium sativum & $\begin{array}{l}\text { Ação antimicrobiana, efeitos antivirais, } \\
\text { atividades imunológicas e antioxidante. }\end{array}$ \\
\hline Babosa & Aloe vera & $\begin{array}{c}\text { Emoliente, antioftálmica, vulnerária, } \\
\text { vermífuga, têm uso científico comprovado } \\
\text { como cicatrizante. }\end{array}$ \\
\hline Boldo de jardim & $\begin{array}{l}\text { Plectranthus barbatus } \\
\text { Andrews }\end{array}$ & $\begin{array}{l}\text { Tônica, eupéptica, hepática, Azia, dispepsia, } \\
\text { mal estar gástrico, ressaca, gastrite. }\end{array}$ \\
\hline Camomila & Matricaria chamomilla & $\begin{array}{l}\text { Anti-inflamatória, antiespasmódica, } \\
\text { analgésica, antisséptica, antimicrobiana, } \\
\text { anti-helmíntica, cicatrizante. }\end{array}$ \\
\hline $\begin{array}{l}\text { Capim da Lapa } \\
\text { ou } \\
\text { Capim limão } \\
\end{array}$ & Cymbopogon citratus & $\begin{array}{l}\text { Bactericida, antiespasmódico, calmante, } \\
\text { analgésico suave, carminativo estomáquico, } \\
\text { diurético. }\end{array}$ \\
\hline Erva cidreira & Melissa officinalis & $\begin{array}{c}\text { Rejuvenescedora, calmante, antidepressivo, } \\
\text { antialérgico. }\end{array}$ \\
\hline Espinheira Santa & Maytenus ilicifolia & $\begin{array}{l}\text { Antisséptica, tônica, analgésica, } \\
\text { cicatrizante, diurética. }\end{array}$ \\
\hline Erva Doce & Pimpinella anisum & $\begin{array}{l}\text { Digestivo, diurético, tônico geral, } \\
\text { antiespasmódico }\end{array}$ \\
\hline Gengibre & Zingiber officinale & $\begin{array}{l}\text { Estimulante gastrintestinal, aperiente, } \\
\text { carminativo, tônico, expectorante }\end{array}$ \\
\hline Graviola & Annona muricata & Antidiabética, espasmolítica, diurética. \\
\hline Hortelã Pimenta & Mentha piperita & $\begin{array}{l}\text { Carminativa, eupéptica, estimulante, } \\
\text { colagoga, estomáquica, antiemética, } \\
\text { antiespasmódica, analgésica }\end{array}$ \\
\hline
\end{tabular}




\begin{tabular}{|c|c|c|}
\hline Hortelã & Mentha piperita & $\begin{array}{l}\text { Carminativa, eupéptica, estimulante, } \\
\text { colagoga, estomáquica, antiemética, } \\
\text { antiespasmódica, analgésica }\end{array}$ \\
\hline Limão & Citrus limon & $\begin{array}{c}\text { Infecções, dor de cabeça, enxaqueca, } \\
\text { problemas musculares, tosse, resfriado, } \\
\text { asma, contra fungos como a micose, } \\
\text { limpeza de pele oleosa, eliminação de } \\
\text { caspa. }\end{array}$ \\
\hline Manjericão & Ocimum basilicum & $\begin{array}{c}\text { Anti-inflamatórias e anti-bacterianas, } \\
\text { analgésica, antitérmica, antiséptica, } \\
\text { digestiva, emenagoga, expectorante e } \\
\text { sedativa. }\end{array}$ \\
\hline Mastruz & Dysphania ambrosioides & $\begin{array}{c}\text { Tratamento de vermes, devido a sua ação } \\
\text { antiparasitária; antifúngica, antibacteriana, } \\
\text { antisséptica. }\end{array}$ \\
\hline Poeijo & Mentha pulegium & Estimulante, antiespasmódica. \\
\hline Romã & Punica granatum & $\begin{array}{l}\text { Diurética, vermífuga, antisséptica, anti- } \\
\text { inflamatória. }\end{array}$ \\
\hline $\begin{array}{l}\text { Nome } \\
\text { Popular }\end{array}$ & $\begin{array}{l}\text { Nome } \\
\text { Científico }\end{array}$ & Propriedades Terapêuticas \\
\hline Sabugueira & Sambucus nigra & $\begin{array}{l}\text { Depurativo, diaforético.( provoca suor nas } \\
\text { gripes, sarampos etc.) }\end{array}$ \\
\hline Saião & Kalanchoe brasiliensis & $\begin{array}{l}\text { Anti-inflamatório, antimicrobiano, anti- } \\
\text { hipertensivo e cicatrizante. }\end{array}$ \\
\hline $\begin{array}{l}\text { Tansagem } \\
\text { ou } \\
\text { Tanchagem }\end{array}$ & Plantago major & $\begin{array}{c}\text { Anti-inflamatório, antisséptico, expectorante, } \\
\text { antidiarreica, cicatrizante, adstringente, } \\
\text { emoliente, depurativa, laxativa. }\end{array}$ \\
\hline
\end{tabular}

\section{Os resultados do Projeto}

A análise dos resultados aponta para uma proposta interdisciplinar que pode ser utilizada como ferramenta pedagógica, capaz de promover aprendizagem significativa, pois houve o envolvimento dos estudantes em todas as etapas desde a implantação do projeto aos cuidados com os exemplares plantados no horto. Resultados semelhantes foram registrados por Medeiros e Crisostimo (2013) ao trabalhar a importância de utilizar as plantas medicinais na sala de aula.

Destacamos, ainda, o aumento do nível de aprofundamento na construção do conhecimento dos educandos em relação aos conteúdos de Botânica e as propriedades terapêuticas, além de identificar a presença das substâncias químicas nas plantas. Esses resultados são semelhantes aos descrito por Medeiros e Crisostimo (2013). O trabalho de investigação e pesquisa, permitiu, também, que os estudantes buscassem informações em 
grupo, estimulando-os à interação, promovendo, assim, a autoconfiança, favorecendo a sua autonomia.

A pesquisa e a representação das fórmulas estruturais planas de compostos como a boldina, presente no Boldo (Coleusbarbatus benth), planta mais utilizada entre os entrevistados, permitiu a exploração do conceito de carbono assimétrico, possibilitando aos alunos identificar os carbonos assimétricos presentes na fórmula estrutural do composto. Situação semelhante foi abordada positivamente por Regina e Alves (2013), que trabalharam com plantas medicinais e o estudo das funções orgânicas. Essas situações rementem ao depoimento de um estudante, participante do projeto, "quem nunca tomou mastruz com leite para matar verme?" ao estudar o principio ativo do Ascaridol, presente na espécie Mastruz (Dysphania ambrosioides), evidenciando que a relação entre teoria e prática são de grande valia no significado dos conceitos.

A construção do quadro identificando os compostos químicos propiciou aos alunos uma visão sobre como a química está presente nas plantas medicinais. A pesquisa sobre os princípios ativos e a identificação das funções orgânicas presentes aproximou a teoria do cotidiano do aluno, fazendo-os perceber a presença da química em seu dia-a-dia. A análise das fórmulas estruturais planas de compostos como a manita, presente na romã, utilizada para inflamação na garganta (GRANDI, 2017), permitiu a exploração do conceito de carbono assimétrico.

Quanto às propriedades terapêuticas (Quadro 2), é válido destacar a importância de utilizar plantas medicinais como recurso didático, para aproximar a cultura popular das famílias dos alunos ao conhecimento científico. O conhecimento cognitivo promoveu a aprendizagem significativa de conceitos, classificação, além de demonstrar que o uso terapêutico das plantas, quando feito com critérios, só tem a contribuir para a saúde de quem o pratica,

Diante do exposto, é possível inferir que o ensino, quando contextualizado e integrado, permite assimilar conceitos científicos de forma significativa. O processo de ensino-aprendizagem contextualizado é um importante meio de estimular a curiosidade e fortalecer a confiança do aluno. 
Concordamos com Nanni (2004), sobre o papel do ensino por experimentação, pois, entendemos que a importância da experimentação está no seu papel investigativo e na forma como proporciona ao aluno a compreensão dos fenômenos envolvidos no conteúdo abordado.

\section{Considerações Finais}

A realização do projeto relatado neste texto foi, de certa forma, desafiadora, pelas inúmeras situações que se apresentam no âmbito escolar, ao mesmo tempo empolgante, por vislumbrar um projeto em parceria, construído a muitas mãos, no qual a interdisciplinaridade foi expressa, e, como diz Fazenda a "interdisciplinaridade é essencialmente um processo que precisa ser vivido e exercido" (FAZENDA, 2011, p.11)..

$\mathrm{Na}$ aplicação do projeto, com sua apresentação e desenvolvimento da parte teórica, a pesquisa de campo, foi possível verificar o empenho e a participação maciça de todos os alunos da turma, com relatos e contribuições significativas para o desenvolvimento do tema proposto. O levantamento de dados por meio da aplicação do questionário, permitiu que os alunos tomassem conhecimento das plantas mais utilizadas e da forma como elas são preparadas, além de constatar a importância que o tratamento fitoterápico tem para as pessoas na atualidade, e valorizou o conhecimento que cada aluno trouxe da sua família.

Os alunos participaram ativamente de todas as atividades propostas, como nas pesquisas bibliográficas buscando informações sobre plantas tóxicas e plantas medicinais, dados como sua classificação taxionômica e suas divisões, sua composição química, princípios ativos, fórmulas estruturais planas e funções orgânicas presentes, apresentando seus resultados por meio de seminários. Essas ações contribuíram significativamente para o aprendizado, pois, dessa forma, os alunos foram sujeitos de sua aprendizagem.

Considerando a utilização das plantas medicinais pelas famílias, a identificação correta pode contribuir, não apenas para o conhecimento botânico ou sua classificação, mas, sobretudo, para evitar uma intoxicação pelo uso 
indevido, pois as semelhanças morfológicas levam as pessoas ao consumo de uma espécie acreditando ser outra. Sendo assim, destaca-se que o projeto possibilitou esclarecer e visualizar as espécies que são benéficas e alertar para aquelas que têm possível toxidade.

A construção do horto medicinal foi um trabalho significativo, possibilitou a participação efetiva e todos tiveram a oportunidade de opinar em cada etapa. Os próprios estudantes organizaram rodízios para o cuidado das plantas durante a semana. Além da expressão da criatividade, a construção do horto potencializou um resgate etnobotânico, mediante a busca o conhecimento tradicional, incentivado de certa forma aos estudantes a conhecerem as potencialidades do uso das plantas medicinais, assim como o seu preparo, manuseio, armazenamento,e cuidados com o ambiente escolar.

Embora a proposta finalizada, não deixaremos de explorar o potencial do projeto, por exemplo, desenvolver a técnica da cromatografia em coluna para detectar princípios ativos presentes em plantas, experimento que, em função do tempo e a necessidade de cumprir com o cronograma trimestral, deixamos de realizar, embora tenhamos proposto o estudo híbrido para cumprir com o objetivo de identificar o principio ativo.

Podemos afirmar que o presente projeto enquadra-se em uma prática exitosa, pois permitiu a relação entre a prática e a teoria, o saber popular e o conhecimento científico. Partimos do pressuposto de que se faz necessário transpor didaticamente os temas oriundos do senso comum e aqueles que são fruto da produção histórica e científica, cuja transmissão é efetivada pela escola. Essa transposição torna o conhecimento facilmente assimilável, configurando a aprendizagem em um processo harmonioso de maturação de conduta, resultando da relação entre professor, aluno e conhecimento, além de se configurar em uma ferramenta didática pedagógica, pois, esse tema assume caráter de formação não apenas escolar, mas também social, associando a vivência de cada indivíduo com as questões discutidas em sala.

O uso de imagens, gráficos e tabelas possibilitou aos estudantes interpretar os resultados, incluindo fazer a leitura de imagens, demonstrando a importância em se trabalhar metodologias que possibilitem aos alunos 
interagirem com o conhecimento, por meio de recursos diversificados, como a análise estatística aliada à informática, a evolução da internet que atrai cada vez mais, e está sendo realidade para muitos alunos na prática diária atualizando conceitos. Sendo assim, o professor deve buscar unir teoria e prática, análise e produção, pesquisa e demonstração.

É notória a mudança comportamental dos estudantes em relação à aprendizagem e contextualização dos conceitos abordados após o desenvolvimento do projeto, incluindo em apresentações e pesquisas posteriores, o que nos leva a acreditar no potencial da proposta, pois percebemos um avanço na participação nas disciplinas envolvidas por parte dos alunos. Somente a participação não determina mudanças na assimilação de conceitos, mas, dados os resultados apresentados neste texto, pode-se afirmar que foi possível estimular o gosto pela investigação científica tornando as disciplinas de Biologia e Química mais atrativa aos estudantes.

\section{Referências}

ALONSO, J.R. Tratado de fitomedicina - bases clínicas e farmacológicas". Buenos Aires, Argentina. Editora Isis. 1998.

AMORIM, D. S. Fundamentos de sistemática filogenética. Ribeirão Preto: Editora Holos, 2002.

AUSUBEL, D. P.; NOVAK, J. D.; HANESIAN, H. Psicologia Educacional. Tradução de Eva Nick et al. Rio de Janeiro, Interamericana, 1980. Tradução de Educational psychology, New York: Holt, Rinehart and Winston, 1978.

CERVO, A. L.; BERVIAN, P. A.; SILVA, R. Metodologia Científica. 6 ed. São Paulo: Pearson Prentice Hall, 2007.162p.

CHASSOT, A. Para que(m) é útil o ensino. Canoas: ed.da Ulbra, 1995.

FAGUNDES, N. C. A; OLIVEIRA, G.L.; SOUZA, B.; G. Etnobotânica de plantas medicinais utilizadas no distrito de Vista Alegre, Claro dos Poções - Minas Gerais. Revista Fitos, Rio de Janeiro, Vol. 11(1), 1-118, 2017 | e-ISSN: 24464775 | www.revistafitos.far.fiocruz.br.

FAZENDA, I. C. A. (org.). O que é interdisciplinaridade? São Paulo: Cortez, 2008.

FAZENDA, I. C. A. (org.). Práticas interdisciplinares na escola - 12 ed. São Paulo: Cortez, 2011a. 
FREIRE, P. Pedagogia da autonomia: saberes necessários à prática educativa. 43. ed., São Paulo: Paz e Terra, 1996.

GRANDI, T. S. M. Tratado das Plantas Medicinais. Disponível em: $<$ https://ciclovivo.com.br/vida-sustentavel/bem-estar/livro-gratuito-reunedetalhe-de-quase-400-especies-de-plantas-medicinais/>Acesso em julho 2019

LÜCK, H. Pedagogia interdisciplinar: fundamentos teórico-metodológicos. Petrópolis: Vozes, 1995. 92 p.

MARTINS, E.R. et al. Plantas medicinais. Viçosa: UFV Imprensa Universitária, 2003. 220 p.

MEDEIROS, E. T. O.; CRISOSTIMO, A L. A importância da aprendizagem das plantas medicinais no ensino da botânica. Disponível em:< http://www.diaadiaeducacao.pr.gov.br/portals/cadernospde/pdebusca/producoe s_pde/2013/2013_unicentro_cien_artigo_edilmari_taques_de_oliveira.pdf $>$ acesso em junho $\overline{2} 019$.

MORGADO, F. S. A horta escolar na educação ambiental e alimentar: experiência do Projeto Horta Viva nas escolas municipais de Florianópolis. 2006. 45p

MAROCHIO, M. R; OLGUIN, C. F. A. Plantas medicinais e o estudo das funções orgânicas. Disponível em:< http://www.diaadiaeducacao.pr.gov.br/portals/cadernospde/pdebusca/producoe s_pde/2013/2013_unioeste_qui_artigo_maria_regina_marochio.pdf >Acesso em julho 2019

NANNI, R. A natureza do conhecimento científico e a experimentação no ensino de Ciências. Revista Eletrônica de Ciências. v.26, maio 2004.

OLIVEIRA, E. B. A interdisciplinaridade na perspectiva de integrar as disciplinas da área de ciências da natureza e matemática. 2016. $221 \mathrm{f}$. Dissertação (Mestrado em Ensino na Educação Básica) - Universidade Federal do Espírito Santo, Centro Universitário Norte do Espírito Santo. 2016.

OLIVEIRA, E. B.; SANTOS, F .N. Pressupostos e definições em interdisciplinaridade: diálogo com alguns autores. Interdisc., São Paulo, no . 11, pp. 01-151, out. 2017.

SILVA, A. M. da. Proposta para Tornar o Ensino de Química mais Atraente. Universidade Estadual do Ceará, Fortaleza - Ceará: RQI, 2011. Disponível em: . http://www.abq.org.br/rqi/2011/731/RQI-731-pagina7-Proposta-para-Tornar-oEnsino-de-Quimica-mais-Atraente.pdf. Acesso em: maio,2020.

SIMPSON, G. G. Princípios da Taxonomia Animal. $2^{\mathrm{a}}$ ed. Tradução de Fernando Albano Ilharco. Lisboa: Fundação Calouste Gulbenkian, 1962.

THIOLLENT, M. Metodologia da pesquisa-ação. São Paulo: Cortez \& Autores Associados, 1988. 
Plantas Medicinais - Aromáticas - Condimentares - Alimentícia Não Convencional (PANC) - $\quad$ Funcionais. Disponível em:<https://www.ppmac.org/acesso> em julho 2019.

\section{Sobre os Autores}

Elisandra Brizolla de Oliveira

ebbrizolla@gmail.com

\section{Biagio Sartori Sampaio}

biagiosartori@gmail.com

\section{Amabele Figueiredo Gomes Borges}

amabellefigueiredo@yahoo.com.br

\section{Franklin Noel dos Santos}

tornus@gmail.com 